\title{
Jornal escolar: gêneros e letramento midiático no ensino-aprendizagem de linguagem
}

\author{
School newspaper: genres and media literacy \\ in language teaching-learning
}

Adair Bonini*

Universidade Federal de Santa Catarina

Florianópolis - Santa Catarina / Brasil

RESUMO: Este artigo, focalizando o jornal escolar, discute o ensino-aprendizagem de linguagem a partir dos conceitos de gênero e letramento. Inicialmente apresenta, em termos do contexto brasileiro, um painel com as discussóes e metodologias recentes sobre ensino-aprendizagem de linguagem. Em seguida, o artigo traz um breve panorama do trabalho com jornal na escola e uma análise de pesquisas que envolvem experiências com jornal escolar. Na parte final, apresenta uma proposta de trabalho com o jornal escolar, que também serve de pano de fundo para outras reflexōes.

PALAVRAS-CHAVE: gênero textual; letramento; ensino-aprendizagem; jornal escolar; jornal.

ABSTRACT: This article, focusing on the school newspaper, discusses the language teaching-learning from the concepts of genre and literacy. It is initially presents, in terms of the Brazilian context, an overview of the recent discussion and methodologies on language teaching-learning. Then, the article provides a brief overview of the work with newspaper at school and a review of studies involving experiments with school newspaper. Toward the end, we present a proposal to work with the school newspaper, which also serves as a backdrop for other reflections.

KEYWORDS: genre; literacy; teaching-learning; school newspaper; newspaper.

\section{Introdução}

O jornal escolar se tornou um importante instrumento de ensinoaprendizagem de linguagem em muitos países, desde a experiência seminal de Freinet (1974), iniciada em 1924. No Brasil, contudo, apenas mais recentemente

*adbonini@yahoo.com.br 
se tem investido em experiências desse tipo. Além disso, existem poucas pesquisas que relatem e analisem essas experiências, de modo que ainda pouco se sabe sobre como são produzidos esses jornais e que lugar ocupam no conjunto dos conteúdos ensinados na disciplina de Língua Portuguesa.

Em termos do ensino de linguagem, o trabalho com o jornal ganhou novos contornos e maior relevância com renovação do currículo e das metodologias de ensino operada pelos Parâmetros Curriculares Nacionais PCN (BRASIL, 1998) ${ }^{1}$ e pela ampliação do debate sobre o ensino de linguagem realizada no interior dos estudos de gêneros textuais / discursivos (DIONÍSIO; MACHADO; BEZERRA, 2002; KARWOSKI, A. M.; GAYDECZKA, B.; BRITO, 2006; BONINI; FURLANETTO, 2006; BONINI; FIGUEIREDO; BAZERMAN, 2009) e dos letramentos (KLEIMAN, 1995; SOARES, 1998; OLIVEIRA; KLEIMAN, 2008; KLEIMAN; BALTAR, 2008; ROJO, 2009).

Além disso, o jornal escolar se revela um dos instrumentos mais apropriados para o desenvolvimento da metodologia dos projetos didáticos (HERNANDEZ; VENTURA, 1998; KAUFMAN; RODRIGUEZ, 1995) que aparece nos PCN (BRASIL, 1998, p. 87) como uma das formas centrais de trabalho com a linguagem na escola. A relação privilegiada com essa metodologia deve-se à importância social do jornal, a sua tecnologia de relativamente simples implementação, e às possibilidades de autoria e protagonismo que ele oferece a alunos, professores e comunidade escolar de modo geral.

Considerando-se esse contexto favorável, o jornal poderia ser mais bem aproveitado no trabalho escolar com a linguagem, de modo que há vantagens na pesquisa e na discussão desse assunto. Neste trabalho, portanto, tendo as metodologias de ensino-aprendizagem de linguagem como pano de fundo, pretendo tecer uma reflexão quanto a experiências pedagógicas realizadas com jornal escolar e, com base nessa reflexão, apresentar uma proposta de trabalho.

\footnotetext{
${ }^{1}$ A discussão que deu origem aos PCN teve início no final da década de 70 e seus resultados podem ser vistos em trabalhos clássicos, como os de Geraldi (1981a, 1981b) e Ilari (1985). Conforme lembra Rodrigues (2008, p. 171): “[e]ssa nova perspectiva propõe a troca do ensino de uma teoria gramatical e suas categorias (ensino sobre a língua) por um outro objeto de ensino, a prática de escuta, de leitura e de produção textual (oral e escrita), articulada com a prática de análise linguística (prática de reflexão sobre a linguagem; ou seja, um outro objeto de ensino e não um novo termo para o ensino de teoria gramatical)".
} 
Nas seções a seguir, faço, primeiramente, um apanhado quanto às metodologias de ensino-aprendizagem de linguagem. Em seguida, procuro descrever e analisar o panorama do trabalho com jornais em sala de aula. Por último, faço a exposição de uma proposta de trabalho com jornal escolar, tendo em conta as turmas dos anos finais do ensino fundamental.

\section{Metodologias de ensino-aprendizagem de linguagem}

Pensar as metodologias de ensino-aprendizagem de linguagem implica considerar, de partida, como está organizado o ensino de Língua Portuguesa no Brasil desde meados da década de 90, o que exige ainda um breve histórico.

Em um texto já clássico em termos do debate brasileiro sobre ensino de linguagem, Geraldi (1981a, p. 41) aponta três concepções de linguagem que têm embasado as metodologias de ensino nessa área: a) a linguagem é a expressão do pensamento (gramática tradicional); b) a linguagem é um instrumento de comunicação (linguística estruturalista e o gerativismo); e c) a linguagem é uma forma de interação (linguística da enunciação). Defendendo essa terceira posição, e se atendo ao então primeiro grau e hoje ensino fundamental, ele propunha: "as atividades devem girar em torno do ensino da língua e apenas subsidiariamente se deverá apelar para a metalinguagem” (p. 45).

É justamente pensando nessa visão de linguagem e em um trabalho com a língua em uso e não apenas com a metalinguagem que Geraldi (1981b, p. 59-79) propóe três unidades básicas para o ensino de linguagem nas escolas: a) a prática de leitura de textos; b) a prática de produção de textos; e c) a prática de análise linguística.

Posteriormente, via PCN (BRASIL, 1998), essas unidades ganham peso de política de ensino no país, e assumem as seguintes denominaçôes: a) prática de escuta e de leitura de textos; b) prática de produção de textos orais e escritos; e c) prática de análise linguística. A duas primeiras são articuladas no eixo do uso e a última, no eixo da reflexão (FIG.1). 


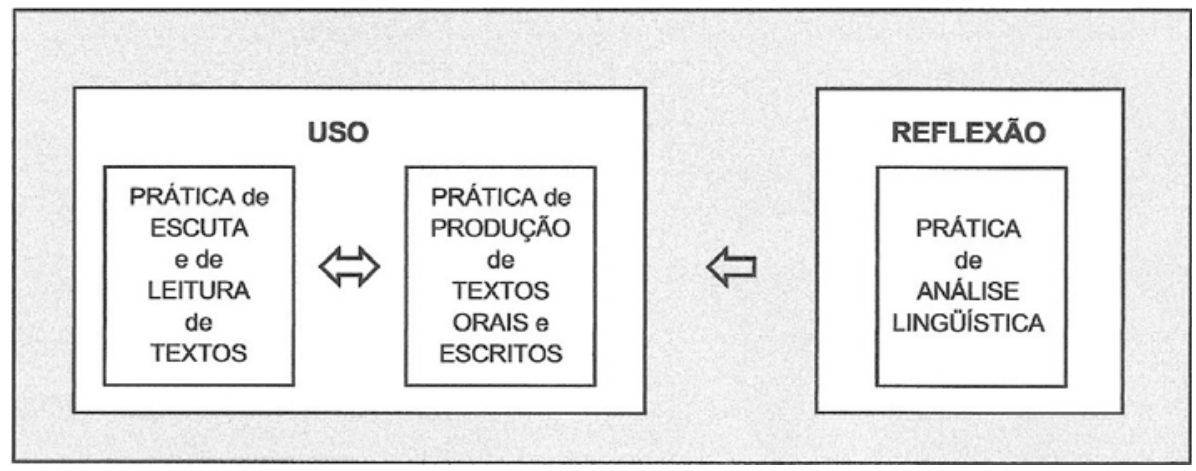

FIGURA 1 - Unidades do ensino de Língua Portuguesa de acordo com os PCN (BRASIL, 1998)

O conceito base para se pensar a operacionalização dessas três unidades de ensino passa a ser o gênero textual (BRASIL, 1998) ${ }^{2}$ que, grosso modo, pode ser definido como a forma de agir e de se enunciar pela linguagem. ${ }^{3} \mathrm{~A}$ noção de gênero vem se somar e dar corpo à intuição inicial de Geraldi (1981b) de um ensino baseado na língua em uso, em atividade. ${ }^{4}$

Em síntese se pode dizer que o objetivo do ensino de linguagem, conforme a posição dominante nesse debate nas duas últimas décadas, é o desenvolvimento de habilidades de uso (textualização e compreensão de textos) e de reflexão metalinguística sobre esse uso, mas o objeto de ensinoaprendizagem propriamente é, a meu ver, o gênero e as práticas a ele relacionadas. Cabe aqui, contudo, uma complementação. Em anos recentes, o termo letramento se somou positivamente a esse debate, uma vez que possibilitou pensar uma série de aspectos da educação linguística até então pouco visíveis ou negligenciados. ${ }^{5} \mathrm{O}$ termo letramento, segundo Rojo (2009):

${ }^{2}$ Nos PCN (BRASIL, 1998), há a opção pelo conceito de gênero de Bakhtin (1953) de modo que, mesmo não aparecendo explicitamente, o termo encampado é "gênero discursivo". Na literatura, contudo, aparecem denominaçōes alternativas, entre elas o termo "gênero textual" que está sendo utilizado no presente artigo.

${ }^{3}$ Existem diversos conceitos teóricos de gênero, sendo que o de Bakhtin (1953) é um dos mais conhecidos: os gêneros são "tipos relativamente estáveis de enunciados" (p. 269).

${ }^{4}$ Em 1981, o debate sobre gênero textual/discursivo no ensino de linguagem ainda não estava instaurado, de modo que Geraldi não utiliza este termo em seus textos. Sua visão da linguagem como prática social, contudo, é completamente compatível com o que veio a se estabelecer mais tarde através da noção de gênero.

${ }^{5}$ Para mais informaçōes sobre esse tema, conferir: Kleiman (1995), Soares (1998), Oliveira e Kleiman (2008), Kleiman e Baltar (2008), Rojo (2009). 
busca recobrir os usos e práticas sociais de linguagem que envolvem a escrita de uma ou de outra maneira, sejam eles valorizados ou não valorizados, locais ou globais, recobrindo contextos sociais diversos (família, igreja, trabalho, mídias, escola, etc.), numa perspectiva sociológica, antropológica e sociocultural (p. 98).

O conceito de letramento nos fez ver que o ensino de leitura e escrita envolve questōes complexas e decisões difíceis. A distinção, de Street (1984), ${ }^{6}$ entre letramento autônomo e ideológico permite concluir que as práticas letradas não são alheias aos jogos de poder e às visões de mundo em disputa; o conceito de letramento local e a distinção entre os letramentos vernacular e dominante de Barton e Hamilton (1998) 7 permite verificar que os letramentos são complexos e múltiplos (TYNER, 1998; COPE; KALANTZIS, 2000), incluindo, entre outros, o letramento midiático (BUCKINGHAM, 2003). É em função desse panorama que Rojo (2009, p. 107-108) ressalta a importância de a educação linguística levar em conta, "de maneira ética e democrática": a) os multiletramentos ou letramentos múltiplos (considerando os letramentos locais e colocando-os para interagir com os letramentos valorizados); b) os letramentos multissemióticos (de grande importância em um mundo dominado pelas mídias de massa e pela internet); e c) os letramentos críticos e protagonistas (favorecendo o trato ético dos discursos e empoderando indivíduos e comunidades).

Desse modo, além dos gêneros textuais, são objetos da educação linguística, os letramentos múltiplos (dos locais de trabalho, das comunidades de bairro, literário, cinematográfico, televisivo, musical, imagético, digital,

${ }^{6}$ De acordo com Street (1984), o letramento autônomo corresponde à visão, dominante na escola tradicional, de que as práticas letradas são descoladas dos usos e das relaçôes de poder na sociedade. Já o letramento ideológico diz respeito à visão de próprio autor de que essas práticas são heterogêneas e valoradas diferentemente de meio para meio, de modo que cabe à escola evidenciar e tirar proveito da natureza dessas práticas para levar os alunos a uma atitude crítica e a uma ação protagonista (de intervenção no meio).

${ }^{7}$ De acordo com Barton e Hamilton (1998) os letramentos são localizados, ou seja: "Ler e escrever são coisas que as pessoas fazem, seja a sós ou com outras pessoas, mas sempre em um contexto social - sempre em um local e em um tempo" (p. 23 - tradução minha). Para esses autores, os letramentos podem ser dominantes - as práticas letradas de maior prestígio e poder na sociedade - ou vernacular - aquelas práticas enraizadas nas experiências e nos propósitos cotidianos que, em geral, têm menor prestígio e são, de algum modo, informal, secretas e privadas (p. 251). 
etc.). A relação entre gênero textual, evento e a prática de letramento ${ }^{8}$ é muito plausível e articulável de diversos modos.

Para que as unidades curriculares pressupostas pelos PCN (BRASIL, 1998) sejam postas em marcha, na educação básica, em harmonia com os conceitos de gênero textual e letramento, alguns métodos de ensinoaprendizagem de linguagem têm sido propostos e / ou incorporados ao contexto brasileiro. Os próprios PCN sugerem, sob o rótulo "organizações didáticas especiais", o desenvolvimento de projetos e módulos ou sequências didáticas. Considerando o que tem aparecido na literatura, faço aqui a descrição do que considero ser os principais métodos de trabalho com linguagem na escola:

a) projeto didático - consiste em uma atividade proposta e realizada consensualmente por alunos e professor e que, ao final, leva à realização de um produto que é posto em circulação (HERNANDEZ, 1998; HERNANDEZ; VENTURA, 1998; KAUFMAN; RODRIGUES, 1995; ZEN, 2002). Conforme apontei em trabalho anterior (BONINI, 2006b), nas experiências relatadas na literatura, aparecem três tipos projetos: temático (atividades voltadas para um tema, como "efeito estufa", mas sem um produto final); temático com produto final (o estudo da Antártida, por exemplo, para, ao final, se fazer uma exposição dos achados); e prático (que tem, já de partida, uma atividade fim como fio condutor: por exemplo, uma "campanha de esclarecimento no bairro"). O primeiro tipo, por não apresentar um produto final, não deve ser entendido como projeto didático. Os projetos, principalmente na forma de projetos de letramento (KLEIMAN, 2000), ${ }^{9}$ são a forma mais efetiva de pôr em marcha o ensino

\footnotetext{
${ }^{8}$ Segundo Barton e Hamilton (1998, p. 7), enquanto o evento de letramento identifica a ocorrência de uma situação social na qual a escrita assume um papel central, a prática de letramento, que diz respeito aos "modos culturais de utilização da escrita", corresponde às relações sociais que se estabelecem em torno dos usos escritos. Os eventos de letramento têm base na prática de letramento que, sendo um nível mais abstrato, somente pode ser vista por meio desses eventos.

${ }^{9}$ Conforme Kleiman (2000), o projeto de letramento é "uma prática social em que a escrita é utilizada para atingir algum outro fim, que vai além da mera aprendizagem da escrita (a aprendizagem dos aspectos formais apenas), transformando objetivos circulares como 'escrever para aprender a escrever' e 'ler para aprender a ler' em ler e escrever para compreender e aprender aquilo que for relevante para o desenvolvimento e realização do projeto" (p. 238).
} 
de linguagem do modo como tem sido concebido mais recentemente, uma vez que eles tanto favorecem o trabalho com os gêneros quanto levam os alunos a uma possibilidade de protagonismo social, além de poderem encampar com facilidade os vários letramentos que existem na sociedade;

b) sequência didática - é um conjunto de atividades de ensino-aprendizagem que se organiza em torno de um gênero oral ou escrito, passando pelas fases da "apresentação da situação", da "produção inicial", dos "módulos específicos" e da "produção final" (DOLZ; NOVERRAZ; SCHNEUWLY; 2004). As produçóes inicial e final servem como forma de se determinar o desenvolvimento dos estudantes durante a sequência, e como modo se realizar uma avaliação formativa;

c) portfólio - trata-se do arquivamento sequencial dos trabalhos de cada estudante de modo que professor e aluno possam avaliar o que foi feito, como, e quais foram os pontos em que houve aprendizagem e desenvolvimento (JOHNS, 1997, 2002);

d) retextualização - é uma técnica proposta por Marcuschi (2001), que consiste na transposição de um registro oral para o escrito e vice-versa. Segundo o autor, a retextualização facilita o desenvolvimento da consciência das diferenças entre as modalidades oral e escrita e o reconhecimento do contínuo de gêneros existentes entre esses dois pólos. Outros autores têm trabalhado com esse método (GAGO; VIEIRA, 2006; DELLISOLA, 2007). ${ }^{10}$

Ganham relevo nesse contexto também as discussões sobre a relação entre conhecimento científico e conhecimento escolar. Para caracterizar essa relação, Chevallard (1989) propõe a expressão "transposição didática do conhecimento científico". Halté (1998), contudo, vendo na escola um lugar social que tem sua própria elaboração de saberes, questiona a ideia de uma "transposição", propondo a expressão "elaboração didática dos conteúdos científicos".

\footnotetext{
${ }^{10}$ De modo geral, esses métodos podem ser operados uns dentro dos outros (por exemplo, a sequência dentro de um projeto didático, ou a retextualização dentro de uma sequência didática).
} 


\section{O jornal e a escola}

No contexto brasileiro, o interesse pelo trabalho com o jornal no ambiente escolar parecer estar se ampliando, haja vista o aumento recente do número de pesquisas e de experiências de produção de jornais escolares. Além disso, o trabalho com jornais nas escolas tem se intensificado principalmente com duas iniciativas de grande porte.

A primeira delas é a recente tentativa das empresas jornalísticas de implementar projetos de utilização do jornal na escola. Teixeira (2005) aponta a existência de 40 programas desse tipo no Brasil. Cabe aqui, entretanto, uma palavra de cautela: se o trabalho com o jornal se restringe aos interesses da empresa, acaba ocorrendo não um letramento sobre a mídia, mas um letramento para a mídia. ${ }^{11}$ É nesse sentido que soa como precaução a afirmação da autora de que: "a maioria absoluta desses projetos objetiva incentivar a leitura de jornal nas escolas brasileiras, o que, apesar de ser uma iniciativa bastante válida, restringe por demais as possibilidades de apropriação dos potenciais de intersecção entre mídia e educação" (p. 5). Vale lembrar ainda o que ressalta Baltar quanto ao trabalho com letramento midiático nas escolas:

Embora muitos professores não se dêem conta, a reprodução do letramento escolar autônomo, mesmo que involuntariamente, acaba ratificando o estado de coisas posto pelas forças das ordens dominantes de poder a quem não interessa a formação de sujeitos protagonistas sociais, mas, sim, o fabrico e a manutenção de uma legião de técnicos e de consumidores à mercê das leis nem sempre consensuais "de mercado". [...] Saber ler os discursos e as formações discursivas das diversas esferas sociais é condição sine qua non para agir autonomamente em sociedade. Um exemplo recorrente que costumamos referir é do professor que trabalha sistematicamente com textos retirados de determinada revista ou jornal sem se dar conta de que os textos estão impregnados da ideologia da revista, jornal; do seu discurso, do discurso de seus donos, dos seus anunciantes e de quem eles representam (p. 20 e 23).

\footnotetext{
${ }^{11}$ Quando me refiro à mídia nesse artigo, estou considerando uma formulação que esbocei em um artigo anterior, ainda inédito, ou seja trata-se de: "[t]ecnologia de mediação da interação linguageira e, portanto, do gênero como unidade dessa interação. Cada mídia, como tecnologia de mediação, pode ser identificada pelo modo como caracteristicamente é organizada, produzida e recebida e pelos suportes que a constituem" (BONINI, mimeo).
} 
Questionáveis ou não, não é possível ter uma noção mais clara quanto ao teor e a função desses programas, uma vez que eles, embora já tenham sido objeto de estudo (BARONI, 2005), não passaram suficientemente pelo crivo da reflexão acadêmica. Mesmo não existindo pesquisas mais abrangentes sobre o tema, não há dúvida, contudo, de que o impacto desses programas sobre a sociedade é imenso, a julgar pelas 1312 escolas e pelos 850.000 alunos atendidos pelo programa do Jornal A Notícia (o AN Escola), no Estado de Santa Catarina (STÜPP, 2008). ${ }^{12}$

A segunda dessas iniciativas na educação, um grande projeto social de fomento da produção de jornais escolares, é o Programa Jornal Escola, desenvolvido sob a coordenação da ONG Comunicação e Cultura. Atualmente, segundo dados do Portal do Jornal Escolar (PORTAL, 2009), o projeto alcança seis Estados da região nordeste, atingindo 1128 escolas: Ceará (471), Piauí (147), Paraíba (127), Rio Grande do Norte (85), Bahia (25), Pernambuco (3). O Programa Jornal Escola, ao atender públicos distintos com suas especificidades próprias, se subdivide em quatro subprojetos:

- Primeiras Letras: jornais escolares publicados nos anos iniciais do ensino fundamental;

- Fala Escola: jornais escolares publicados nos anos finais do ensino fundamental;

- Clube do Jornal: jornais estudantis publicados no ensino médio;

- Jornais Juvenis Associados: promove a formação de grupos juvenis dispostos a produzir jornais comunitários como instrumentos de expressão jovem e mobilização comunitária (PORTAL, 2009).

Em anos mais recentes, a construção de uma intersecção entre as Ciências da Comunicação e da Educação, em um campo de atuação denominado Educomunicação (SCHAUN, 2002), também tem propiciado o aumento tanto de pesquisas quanto de experiências de ensino com o jornal na escola (MIRANDA, 2006; SOBREIRO, 2008; TEIXEIRA, 2005).

Ainda são poucos os relatos de experiências com o jornal escolar, mas elas vêm aumentando. Em uma varredura realizada no dia 16 de outubro de 2009, no banco de teses da CAPES, em termos das décadas de 1990 e 2000,

${ }^{12}$ O jornal A Notícia tem sede em Joinville (SC) e, desde 2006, pertence ao grupo RBS (Rede Brasil Sul de Comunicação), sediado em Porto Alegre (RS). 
com as palavras-chave "jornal - escola", "jornal - sala de aula", e "jornal escolar", encontrei 11 trabalhos: Augé (2008), Baltar (2003), Cavalcanti (1999), Cavalini (2000), Ijuim (1995, 2002), Salustiano (2000, 2006), Sbrussi (2001), Teixeira (2001), e Torquato (2002). ${ }^{13}$ Considerei apenas as pesquisas que relatavam alguma experiência de produção de jornal pelos alunos. Desses trabalhos, dois foram realizados durante a década de 90 e nove no período 2000 a 2008, o que representa um incremento significativo nessa produção. É importante notar também que, desse montante, apenas um trabalho foi produzido na área de Letras-Linguística (BALTAR, 2003), sendo os demais pertencentes à área de Comunicação (3) e à área da educação (8). A reflexão acadêmica sobre o assunto no país, portanto, tem sido tocada por pesquisadores em três campos - Comunicação, Educação e Linguística - mas, a que tudo indica, com uma participação menor do campo da linguagem (ou pelo menos dos programas de pós-graduação dessa área), seja na condução de pesquisas e debates, seja na proposição de projetos pedagógicos em escolas.

Em termos dos livros contendo relatos desse tipo de experiência, além do clássico livro de Freinet (1974), existem apenas outros dois - Baltar (2004) e Ijuim (2006) - ambos consistindo em adaptações das teses citadas acima. O primeiro deles traz um relato do ponto de vista do ensino de linguagem, focalizando a produção textual e a leitura, em uma perspectiva interacionista sociodiscursiva (cf. BRONCKART, 1997). O segundo centra a sua análise nos depoimentos dos participantes, aplicando uma perspectiva educacional e social, para identificar aspectos experienciais relativos ao envolvimento dos alunos com o jornal por eles produzidos.

Há um terceiro livro que trata do jornal escolar (FARIA; ZANCHETTA JR., 2002), ${ }^{14}$ mas que consiste, diferentemente dos anteriores, em uma

\footnotetext{
${ }^{13}$ Um dos trabalhos levantados (GALARZA, 1988) não está sendo citado, pois foi elaborado durante a década de 80 , e não é possível verificar a sua relevância estatística em termos das pesquisas dessa década sobre o tema, uma vez que o Banco de Teses da Capes somente está alimentado com os trabalhos produzidos a partir de 1987. Outro aspecto que precisa ser mencionado é que, infelizmente, ainda não consegui ter acesso à maior parte dessas teses e dissertaçōes. Embora sejam pesquisas relativamente recentes, a disponibilização de trabalhos em ambiente digital na maioria dos programas de pós-graduação apenas começou há dois ou três anos, de modo que a maior parte deles só pode ser acessada com certo dispêndio de tempo e recursos.

${ }^{14}$ Faria publicou outros dois livros sobre o tema $(1989,1996)$, ambos tratando da utilização do jornal como base de atividades pedagógicas, mas não efetivamente da produção de jornais pelos alunos.
} 
proposta de trabalho, não trazendo dados de pesquisa. Esses autores fazem, contudo, um alerta para três problemas a respeito da produção do jornal escolar que precisam ser mencionados aqui, pois, certamente, são aspectos importantes da discussão sobre esse assunto. Segundo eles: 1) esses jornais, com muita frequência, "se limitam a fazer reprodução de matérias" ou transformam-se "em mera apostila de disciplinas, repetindo-se ali, como informação, o resumo de uma aula"; 2) podem também ficar fechados "entre os próprios leitores, o que tira o caráter de divulgação ampla de informações variadas"; e 3) por vezes, se limitam "a apresentar textos pessoais dos alunos, poesias e piadas", trazendo "pouca coisa nova aos alunos".

$\mathrm{Na}$ implementação de um jornal escolar, pode-se privilegiar seu papel de mídia de alunos, sendo que a ênfase nessa perspectiva pode levar a uma experiência sem nenhuma relação com os conteúdos e as práticas da sala de aula. Pode-se privilegiar, por outro lado, sua função como ferramenta de ensinoaprendizagem, sendo que a ênfase nessa perspectiva pode levar a uma experiência de treino, sem nenhuma função interacional e autoral. ${ }^{15}$ Uma parte dos trabalhos procura privilegiar essa primeira perspectiva, a exemplo de Ijuim (2002, 2006), Freinet (1974); outra parte, procura desenvolver uma perspectiva intermediária, a exemplo de Baltar $(2003,2004)$ e Augé (2008), embora esse ponto ainda se revele frágil em ambas as pesquisas, como defenderei mais abaixo. Particularmente, acredito ser mais produtiva a proposição que, além de privilegiar o papel interacional do jornal, procure considerar, logo de início, a sua função como instrumento pedagógico. Por esse motivo, vou me ater um pouco mais a esses últimos trabalhos.

A questão é exatamente a de se conseguir refletir e tomar posições quanto a esse duplo papel do jornal (de ser meio de interação e, ao mesmo tempo, objeto de ensino-aprendizagem) de modo a tirar proveito dessa dupla face. O que ocorre, nas duas experiências aqui consideradas, é que, positivamente, o jornal foi pensado como um instrumento da aprendizagem de leitura e escrita. Os bons resultados que esses professores alcançaram,

\footnotetext{
${ }^{15}$ A reflexão sobre a produção de jornais escolares envolve, de algum modo, o que Schneuwly e Dolz (2004) denominam o "desdobramento do gênero na escola" - o fato de que ele, nesse contexto, é, ao mesmo tempo, objeto de comunicação e de ensino-aprendizagem. O jornal escolar, dentro dessa mesma ótica, deve ter caráter interativo para os alunos, mas, ao mesmo tempo, não deve perder sua especificidade como objeto (e motor) de aprendizagem.
} 
contudo, talvez ainda possam ser melhorados em futuras pesquisas, caso se consiga chegar a um ponto em que haja uma melhor calibragem da participação autoral do professsor e dos alunos na organização da experiência.

Desse modo, em Augé (2008), o jornal produzido apresenta: a) textos copiados (palavra-cruzada, letra de música, etc.) que privilegiam centralmente a diversão e a interação dos alunos; b) textos que equilibram as funções de interação e de aprendizagem no jornal (relatos de pesquisa, por exemplo); e c) textos que tendem a um simulacro do jornal como é praticado fora da escola (ênfase na função de instrumento pedagógico). Podemos notar, nos exemplos 1 e 2, como os classificados produzidos cumprem mais a função de treino do gênero do que de interação com função autoral entre os alunos - daí a clara simulação em 1 e a paródia em 2 . O contrário, uma ação praticamente sem função pedagógica, também se verifica em uma letra de música que apenas é transposta para o jornal - é uma interação autêntica, mas que não mobiliza nenhum conteúdo de aprendizagem.

(1) TROCO OPALA 78, cor branca, rodas 17 ' de liga, por BMW completa. Cel.: 84396640

(2) TROCO um celular Siemens A50 e uma calça velha por um namorado. Condições: bonito, alto, de olhos azuis. Tratar com Natara. Fone: 32226141

Na proposta conduzida por Baltar $(2003,2004)$, os alunos chegaram a experiências autênticas de interação via jornal e, portanto, a práticas do letramento midiático. A organização dos jornais na experiência, contudo, em alguns momentos simula de modo talvez um pouco rígido o jornal convencional (não escolar) (ver FIG. 2). Se os títulos dos jornais (Testemunha ocular; Traficando informaçóes, etc.) parecem refletir projetos autorais dos alunos, o mesmo não ocorre em algumas seções. Economia, política, cultura e esportes são seções típicas dos jornais convencionais e que dificilmente se coadunam com a identidade e os temas próprios (os dizeres) dos alunos; seçôes como história e meio ambiente, em outra direção, têm caráter claramente escolar e, portanto, encampam o projeto enunciativo do(s) professor(es), refletindo a 
ênfase no jornal como instrumento pedagógico, mas não como mídia dos alunos. Em meio a essas seções aparecem também aquelas que equilibram os dois aspectos (ser mídia dos alunos e instrumento pedagógico), como é o caso da seção "Social" (e da matéria "Formatura do ensino médio").

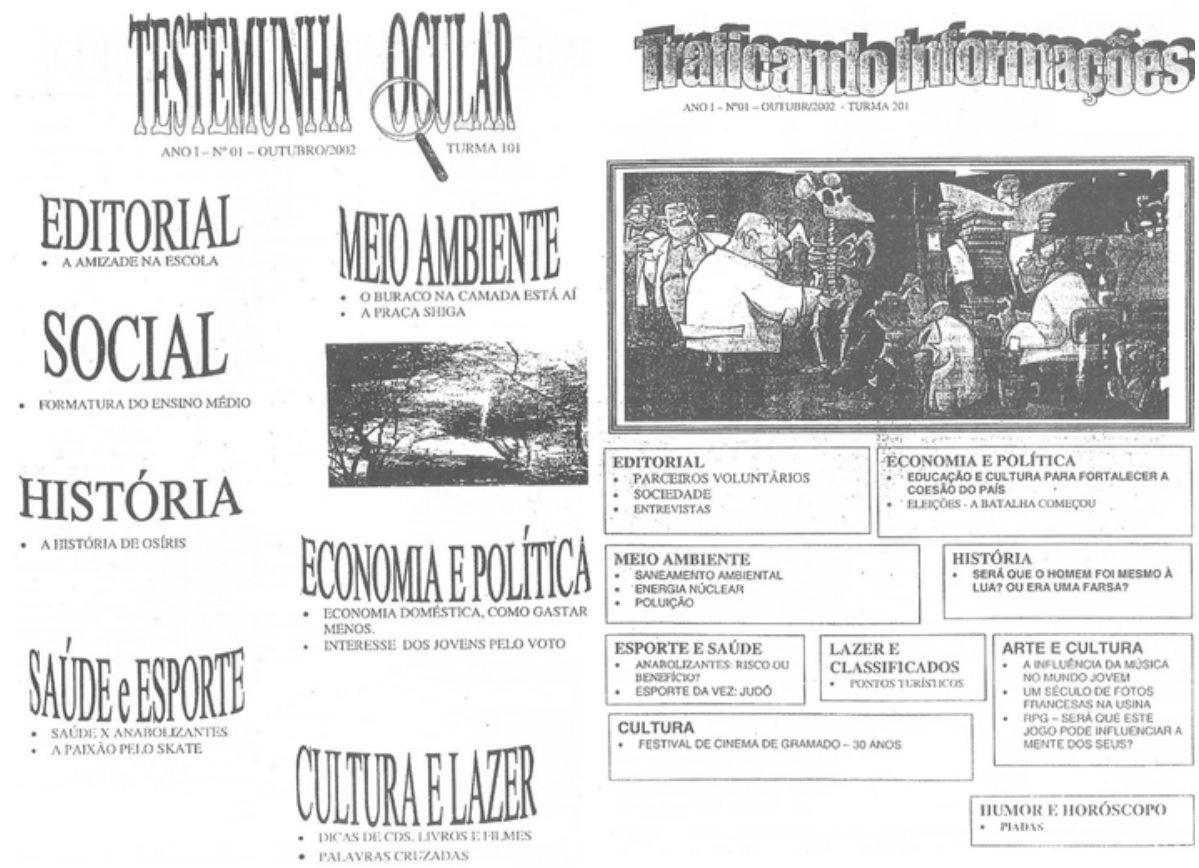

FIGURA 2 - Capas dos jornais produzidos durante a experiência realizada por Baltar (2004)

Em conclusão, tanto Augé (2008) quanto Baltar (2003, 2004) chegam a resultados importantes para a aprendizagem de seus alunos, mas talvez pudessem ter tido um ganho extra, caso esses aspectos complicadores pudessem ter sido calibrados de início. Minha sugestão, portanto, é para que se coloque como ponto central uma reflexão sobre essa dinâmica entre o social (a prática de referência), a escola (a prática escolar e escolarizada) e a construção do protagonismo estudantil (a prática identitária).

De modo geral, parece que o ponto mais delicado, no que tange à produção do jornal escolar, está no fato de que ele não pode ter um caráter de pura mídia dos alunos (uma vez que se perde de vista a especificidade da esfera jornalística, empobrecendo o conteúdo de linguagem a ser apreendido pelo aluno), mas também não pode se tornar um mero simulacro do jornal 
convencional (sob pena de se perder de vista a sua especificidade enunciativa escolar, o que lhe confere valor subjetivo do ponto de vista do aluno como sujeito autor). Nas experiências didáticas aqui analisadas, já há um trabalho no sentido de se considerar ambos os aspectos e com resultados bastante produtivos, mas que talvez pudesse ser intensificado em experiências futuras.

\section{Uma proposta de trabalho com o jornal escolar}

A proposta de projeto que passo a descrever procura equilibrar a dupla face do jornal escolar (mídia dos alunos e instrumento de ensino-aprendizagem). $\mathrm{O}$ modelo de jornal proposto para produção busca, desse modo, ser equilibrado, por um lado, quando à participação de professor(es) e alunos na sua autoria e, por outro, em termos do quanto ele refletirá o jornal convencional (algo necessário para que haja a prática de letramento midiático e jornalístico) e do quanto ele respeitará aqueles sujeitos específicos (que não são jornalistas, mas alunos), possivelmente favorecendo a sua expressão como autores e, portanto, como protagonistas sociais (algo que é necessário para que o jornal exista enquanto mídia de expressão e interação dos alunos). Faço, nesta seção, a exposição, concentrando-me em dois aspectos: a) o modelo de jornal escolar proposto; e b) a articulação desse modelo com o trabalho do professor em termos das metodologias adotadas e de suas operacionalizaçóes.

Seguindo essa linha de orientação, o jornal proposto é pensado como um esquema que respeita diversos gêneros e a organização de um jornal convencional, mas, ao mesmo tempo, é atualizado como uso local, servindo de mídia própria dos alunos e, portanto, como um instrumento de suas identidades e protagonismo. Diferentemente do que propõe Ijuim (2006), aqui os alunos não participam de todas as decisões. Eles assumem o comando do jornal, mas devem, antes e simultaneamente, aprender os gêneros, a linguagem e o trato crítico com essa mídia, o que depende de um nível anterior de planejamento e realização de escolhas por parte do professor.

Nesta proposta, portanto, foi considerado um pequeno conjunto de gêneros do jornal convencional que possibilita, aos alunos, conhecer essa mídia em termos de seus mecanismos textuais e discursivos e que, ao mesmo tempo, pode ser utilizado na montagem de um pequeno jornal escolar que possa funcionar como autêntica mídia dos alunos. O QUADRO 1 possibilita visualizar as seções e os gêneros que as compõem. Apenas os gêneros em negrito seriam objeto de ensino com toda a turma em sala de aula, conforme se verá mais adiante. 
QUADRO 1

Seções e gêneros do jornal escolar proposto ${ }^{16}$

\begin{tabular}{|c|c|}
\hline Seções & Gêneros \\
\hline $\begin{array}{l}\text { [Título] } \\
\text { Capa } \\
\text { (Gêneros } \\
\text { exclusivos dos } \\
\text { alunos editores } \\
\text { e professor) }\end{array}$ & $\begin{array}{l}\text { - Cabeçalho (identifica o jornal) } \\
\text { - Editorial (traz a opinião dos editores e/ou uma descrição da edição) } \\
\text { - Chamada (anuncia os principais textos da edição e a sua localização) } \\
\text { - Expediente (lista com os nomes e funções dos que fazem o jornal) } \\
\text { - Anúncio (divulga e promove marcas e produtos) } \\
\text { - Errata (faz explicação e retificação de erros da edição anterior) }\end{array}$ \\
\hline $\begin{array}{l}\text { [Título] } \\
\text { Opiniāo }\end{array}$ & $\begin{array}{l}\text { - Artigo de opinião (traz a opinião de um colaborador do jornal) } \\
\text { - Enquete (evidencia a opinião dos leitores sobre determinado tema) } \\
\text { - Carta do leitor (traz um comentário sintético do leitor a respeito de texto } \\
\text { publicado na edição anterior, ou da edição como um todo, e sobre } \\
\text { outros temas e fatos) }\end{array}$ \\
\hline $\begin{array}{l}\text { [Título] } \\
\text { Notícias do(a)... }\end{array}$ & $\begin{array}{l}\text { - Notícia (descrição de acontecimento) } \\
\text { - Reportagem de cobertura (descrição do dia a dia de instituição ou } \\
\text { evento duradouro) } \\
\text { - Nota (descrição sintética de acontecimento) } \\
\text { - Entrevista (traz as respostas de uma personalidade sobre fatos e/ou } \\
\text { assuntos) }\end{array}$ \\
\hline $\begin{array}{l}\text { [Título] } \\
\text { Conhecimento } \\
\text { sobre... }\end{array}$ & $\begin{array}{l}\text { - Reportagem didática (descreve assunto, situação-problema ou assunto) } \\
\text { - Reportagem de pesquisa (apresenta dados de interpretação de problema } \\
\text { em evidência ou tendência de comportamento social) } \\
\text { - Carta-consulta (traz a apresentação, pelo leitor, de problema e o } \\
\text { consequente pedido de esclarecimento) }\end{array}$ \\
\hline $\begin{array}{l}\text { [Título] } \\
\text { Ação cultural... }\end{array}$ & $\begin{array}{l}\text { - Programação (apresenta um cronograma de eventos sociais e dados } \\
\text { pontuais de sua ocorrência) } \\
\text { - Crítica de cinema (apresenta a opinião de alguém sobre determinado filme) } \\
\text { - Reportagem de roteiro (descreve ponto turístico) } \\
\text { - Reportagem de perfil (descreve personalidade ou instituição) }\end{array}$ \\
\hline
\end{tabular}

A produção desses gêneros possibilitaria a realização de um jornal com seis páginas, organizado do modo como se pode observar na FIG. 3. Esse esquema de diagramação favorece pensar a materialização do jornal, o trabalho e as etapas que precisam ser realizadas, e o tipo de mediação que estará a cargo

${ }^{16}$ Alguns dos gêneros considerados nesse quadro foram descritos em trabalhos meus ou de meus orientandos. É o caso das várias formas da reportagem que aparecem descritas em Bonini (2009). 
do professor. No modelo proposto, as seções podem ser assim explicadas e justificadas:

a) Capa - funciona como o ponto de unificação do jornal como unidade de interação (uma vez que, por exemplo, a capa se remete aos textos da edição, sumarizando-a, aglutinando-a). Além disso, elementos como o nome do jornal (escolhido pelos alunos durante a montagem da linha editorial) e os conteúdos tratados nas chamadas representam o primeiro e principal ponto de identificação dos alunos com o jornal escolar como mídia que lhes atende;

b) Opinião - é a seção na qual os alunos podem expressar o que pensam sobre os fatos que dizem respeito ao campo de abrangência do jornal, noticiados ou não no jornal. Ao mesmo tempo em que podem desenvolver as habilidades da argumentação e da exposição, os alunos podem se ver representados ao publicar o seu ponto de vista ou ao ler e confrontar o ponto de vista do colega;

c) Notícias do(a)... [do colégio, do bairro, do movimento $x$, etc.] - nesta seção, ao mesmo tempo em que os alunos se apropriam dos principais gêneros do jornal convencional (nota, notícia, reportagem e entrevista) - e, portanto, têm uma evidente experiência de letramento midiático jornalístico - eles também desenvolvem um conteúdo que torna esse jornal produzido um autêntico jornal de alunos (e, portanto, escolar), uma vez que os fatos cobertos não exigem que o alunos finjam estar em outra situação (como seria se a seção se chamasse, por exemplo, notícias da bolsa de valores ou notícias do congresso);

d) Conhecer sobre... - é uma seção na qual os alunos podem abordar temas específicos dentro do campo de abrangência (da linha editorial) do jornal. Tanto pode ter, em relação ao gênero carta-consulta, uma seção fixa (do tipo pergunte ao professor) ou um tema e especialista diferentes por edição, podendo esse especialista ser alguém da comunidade. Na outra parte dessa seção, apareceriam reportagens que descreveram conteúdos: a reportagem didática (que explica um assunto, situação-problema ou serviço) ou a de pesquisa (que aporta dados de interpretação de problema em evidência ou de tendência de comportamento social); 


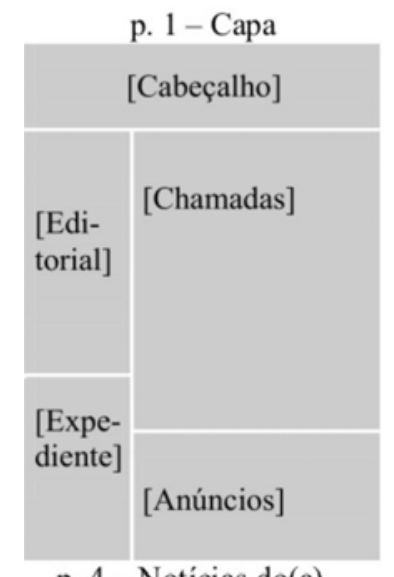

p. 4 - Notícias do(a)...

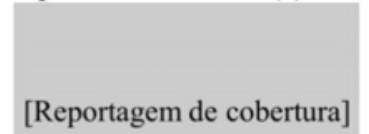

[Entrevista] p. 2 - Opinião
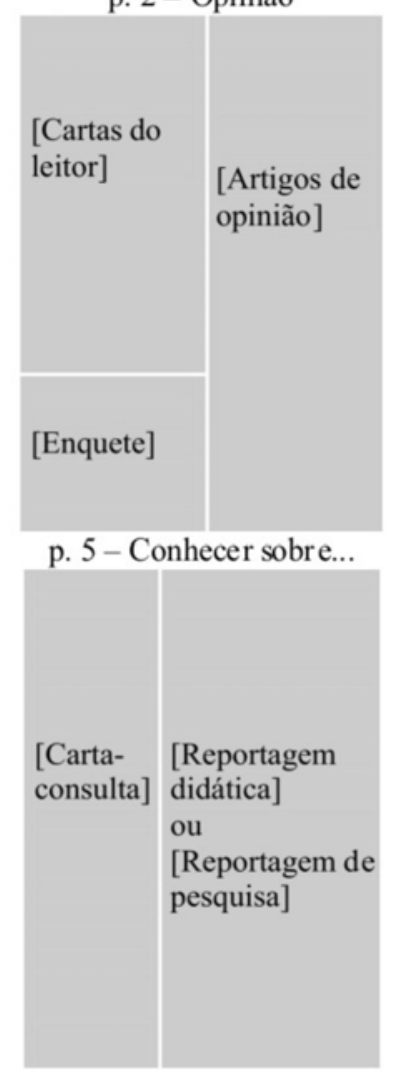

p. 3 - Notícias do(a)...

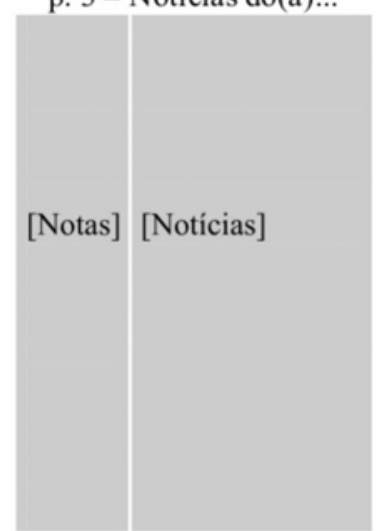

p. 6 - Ação cultural

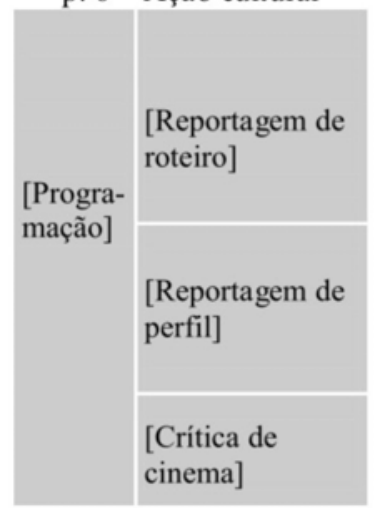

FIGURA 3 - Esquema de diagramação do jornal escolar proposto

e) Ação cultural - é a seção que possibilita aos alunos organizar atividades culturais e falar a respeito delas, podendo (e talvez até devendo) ser abordadas também outras formas de acesso à cultura - o cinema, a locadora, a televisão. A princípio, podem aparecer, nessa seção, quatro tipos de informação, cada uma delas em um gênero: lista de eventos (no gênero programação), informações sobre um ponto turístico (na reportagem de roteiro), informações sobre uma personalidade - de dentro ou fora da escola - ou sobre uma instituição (na reportagem de perfil) e a opinião dos alunos sobre um filme, por exemplo, que tenha chegado recentemente à locadora do bairro e que tenha relação com a linha editorial escolhida para o jornal. 
Todos os gêneros publicados no jornal proposto podem ser complementados com gêneros auxiliares - aqueles que apresentam a informação de outro modo ou a destacam, muitas vezes com recursos multimodais, sendo exemplos: o cineminha, a cronologia, a ficha técnica, a fotografia, a galeria, a grade, o gráfico, o infográfico, a ilustração, a lista, o mapa, o story-board, e a tabela. É dificil saber com quantos e com quais desses gêneros se poderia trabalhar, mas muitos deles certamente não estariam presentes em um primeiro momento do projeto. É bastante plausível, entretanto, que a fotografia seja um dos primeiros gêneros desse conjunto a ser trabalhado, considerando-se a praticidade do seu uso no contexto atual (com as máquinas fotográficas digitais) e a sua importância como recurso jornalístico.

Se o esquema da FIG. 3 visa, de antemão, harmonizar as faces que compóem a natureza do jornal escolar, possibilitando um espaço de intervenção pedagógica, ele também traz subjacente um espaço de participação dos alunos. Desse modo, são eles que escolhem o nome do jornal, o título das seçōes, os assuntos que serão cobertos e a abordagem. $\mathrm{O}$ jornal pode tratar de algum assunto que mobilize a maior parte do grupo de estudantes: questóes do bairro, da escola, da cidade, podendo ainda se centrar em assuntos como classes sociais, trabalho, minorias sociais, movimento cultural, segurança pública, adolescência, etc. A linha editorial também pode mudar de ano para ano de acordo com os assuntos mais importantes para aquele grupo.

A ideia aqui é a de que o jornal, assim projetado, possa ser desenvolvido pelos quatro anos finais do ensino fundamental, sendo coordenado e editado por alunos do $9^{\circ}$ ano, que seriam os mais experientes, uma vez que teriam passado por um trabalho desse tipo desde o $6^{\circ}$ ano. A opção, nesta reflexão, por um jornal dos anos finais deve-se ao fato de que os anos iniciais estão em outra fase de aprendizagem das práticas letradas e em uma faixa etária também diversa, devendo ter um jornal exclusivo que respeite essas especificidades.

$O$ fato de o conjunto de gêneros ser pequeno e o jornal, relativamente simples, favorece o desenvolvimento de atividades em sala de aula no sentido da aprendizagem desses gêneros e da produção de pelo menos parte dos textos das edições. No todo, o jornal é tocado como um projeto didático das turmas desses quatro anos finais. Internamente, contudo, o projeto é conduzido mediante sequências didáticas para a apropriação de gêneros específicos em cada ano de escolaridade. O QUADRO 2 apresenta uma visualização dos gêneros e dos períodos das sequências didáticas em cada ano. Não é possível detalhar cada sequência no espaço desse artigo. Além disso, esse já é um assunto tratado 
em diversas publicações. De todo modo, é importante que essas sequências envolvam pelo menos a leitura crítica desses gêneros, o estudo de suas condições de produção, a análise de suas organizações e tarefas de produção textual.

QUADRO 2

Cronograma da realização da sequências didáticas.

\begin{tabular}{c|l|l|l}
\hline Ano & Fev. - abr. & Ago. - set. & Out.-nov. \\
\hline $\mathbf{6}$ & Enquete & Carta-consulta & Programação \\
\hline $\mathbf{7}$ & Carta do leitor & Entrevista & Reportagem de roteiro \\
\hline $\mathbf{8}$ & $\begin{array}{l}\text { Notícia } \\
\text { Nota }\end{array}$ & Reportagem de cobertura & Reportagem de perfil \\
\hline $\mathbf{9}$ & Artigo de opinião & $\begin{array}{l}\text { Reportagem didática } \\
\text { Reportagem de pesquisa }\end{array}$ & Crítica de cinema \\
\hline
\end{tabular}

A progressão dos gêneros trabalhados nos anos de escolaridade aqui considerados segue uma lógica de aumento da complexidade e do nível de abstração: menos complexos no sexto ano (programação, por exemplo) e mais complexos no nono ano (artigo de opinião e reportagem de pesquisa). Outro aspecto é que a realização, nesse caso, de três sequências didáticas por ano de escolaridade possibilita que se tenha, consequentemente, três ediçóes do jornal por ano. Além disso, essa progressão das sequências didáticas considera os gêneros na ordem das seções que estruturam o jornal (da página 1 à 6), possibilitando, desse modo, que, no ano de implementação do projeto, sejam produzidos jornais com tamanhos diversos, em ordem crescente nas três ediçôes: a) páginas 1 a 3 na primeira etapa (fevereiro a abril); b) páginas 1 a 5 na segunda etapa (agosto e setembro); e c) páginas 1 a 6 na terceira etapa (outubro e novembro). Nos anos seguintes, todas as edições poderão ter seis páginas, uma vez que todas as turmas em todos os anos finais do ensino fundamental na escola estarão produzindo ou aptos a produzir todos os gêneros essenciais para pôr em funcionamento o jornal escolar proposto, havendo, portanto, material suficiente para as ediçôes.

A distribuição do jornal fica a cargo também dos alunos editores que podem, para facilitar, fazer apenas poucos exemplares impressos para a venda e, posteriormente, afixar em mural e / ou transformar em PDF para que seja disponibilizado no site do colégio.

A montagem das edições também obedeceria a um conjunto de etapas, conforme expóe o QUADRO 3. Nesse conjunto de tarefas, os alunos do $9^{\circ}$ 
ano e o professor seriam responsáveis por selecionar os textos para compor cada número, pela revisão final, diagramação e produção dos gêneros da capa (editorial, chamadas, expediente, e, se for o caso, anúncios). É preciso também que os editores estabeleçam um código de ética relacionado às informações publicáveis, evitando-se, desse modo, linguagem grosseira, ofensas, calúnias, entre outros possíveis problemas da comunicação / interação nessa situação.

QUADRO 3

Cronograma de realização do jornal.

\begin{tabular}{l|c|c|c}
\hline PASSOS & EDIÇAO 1 & EDIÇÃO 2 & EDIÇÃO 3 \\
\hline $\begin{array}{l}\text { Realização das sequências didáticas } \\
\text { (professor e alunos) }\end{array}$ & $\begin{array}{c}\text { Fev., 20 - } \\
\text { abr., 30 }\end{array}$ & $\begin{array}{c}\text { Ago., 1- } \\
\text { set., 15 }\end{array}$ & $\begin{array}{c}\text { Out., 1 - } \\
\text { nov., 15 }\end{array}$ \\
\hline $\begin{array}{l}\text { Coleta do material produzido } \\
\text { (professor e alunos editores) }\end{array}$ & abr., 30 & Set., 15 & Nov., 15 \\
\hline $\begin{array}{l}\text { Seleção do material produzido } \\
\text { (professor e alunos editores) }\end{array}$ & Mai., 1-10 & Set., 16-20 & Nov., 16-20 \\
\hline $\begin{array}{l}\text { Organização do material nas seções do jornal } \\
\text { (professor e alunos editores) }\end{array}$ & Mai., 11-20 & Set., 21-25 & Nov., 21-25 \\
\hline $\begin{array}{l}\text { Escrita dos gêneros da capa } \\
\text { (professor e alunos editores) }\end{array}$ & Mai., 21-30 & Set., 26-30 & Nov., 26-30 \\
\hline Impressão do material (alunos editores) & Mai., 30 & Set., 30 & Nov., 30 \\
\hline Distribuição (alunos editores) & Junho, 1 & Out., 1 & Dez., 1 \\
\hline
\end{tabular}

O tempo gasto com as sequências didáticas - e, portanto, as datas de fechamento das edições - podem ser revistos de acordo com o planejamento do professor. Conforme o projeto avance e professor e alunos ganhem experiência, muito do planejamento pode ser revisto. Além disso, o jornal pode se tornar mais complexo, ampliando-se as seçôes, os gêneros e os letramentos trabalhados. Um exemplo seriam as atividades de letramento literário (COSSON, 2006) que poderiam desembocar no jornal, dependendo de sua linha editorial ou de possível ajuste nessa linha editorial. Poesias, minicontos, notícias de lançamentos e críticas de livros poderiam, assim, ser produzidos e, por sua vez, complementar a seção "Ação cultural" ou compor uma nova seção do jornal.

Conforme o projeto avance, as seçôes produzidas dentro do modelo inicial também podem receber outros gêneros, dependendo da maturidade e do interesse do grupo. Na seção opinião, por exemplo, poderia ser incluída a 
charge, ou, na seção conhecimento, o ensaio. Essas seções também podem ser incrementadas pela reutilização dos mesmos gêneros trabalhados em sala de aula. A entrevista, a nota e a notícia, por exemplo, podem estar presentes em mais de uma delas.

Conforme o professor resolva alocar tempo para outros projetos ou experiências didáticas, o jornal também pode ser reduzido: a) para cinco páginas, correspondendo a duas sequências didáticas anuais por turma; ou b) para três páginas, correspondendo a uma sequência didática anual por turma. Pode-se criar também um jornal por série, centrado em um desses gêneros: jornal de notícias, jornal de entrevistas, de cartas-consulta, etc. Mesmo nas práticas de referência encontramos jornais instaurados com base em um único gênero - como o jornal de resenhas, o jornal de opinião (centrado no artigo de opinião) e o de imóveis (centrado no classificado).

\section{Considerações finais}

Diante das diretrizes propostas para o ensino-aprendizagem de linguagem a partir de meados da década de 90 , uma vez que não existe mais a figura de um programa de conteúdos fixado de antemão, torna-se tarefa do professor determinar as habilidades que os alunos precisam desenvolver, escolher os conteúdos de ensino que favorecerão o desenvolvimento dessas habilidades, e organizar o trabalho com esses conteúdos no tempo escolar. Essas tarefas do professor, embora não representem um problema, são um ponto que merece reflexão por parte de professores na escola e na universidade. É, portanto, essa preocupação com a seleção de conteúdos, com a organização do tempo escolar e com a operacionalização da prática pedagógica que dá base e toma o centro da reflexão no presente artigo. De certo modo, este trabalho é uma continuação de reflexôes anteriores, uma vez que já me ocupei de questões similares em trabalhos prévios (BONINI, 2001, 2002, 2003b).

Este artigo também visa de algum modo pensar a relação dos conteúdos da pesquisa acadêmica com os conteúdos ensinados-aprendidos na escola. A proposta exposta acima é fruto de vários anos de pesquisa sobre os gêneros e a organização do jornal convencional (BONINI, 2009, 2008, 2006a, 2003a). $\mathrm{O}$ conhecimento sobre esses gêneros e práticas, de certa maneira, possibilita que se lance um olhar diferente sobre o jornal escolar, tanto no sentido de rever experiências quanto no sentido de propor diretrizes para outras experiências. Procurei, desse modo, pensar o papel do jornal convencional como um catalisador de práticas de letramento na sociedade, me atendo, nesse caso, aos 
espaços de elaboração desse conhecimento na escola (cf. HALTÉ, 1998).É nesse sentido que o jornal escolar aqui proposto é pensado como uma base para um desenvolvimento futuro, como uma estrutura que se desenvolverá durante a experiência na escola, seja como instrumento de ensino-aprendizagem, seja como mídia própria de interação dos alunos.

Cabe ressaltar, por último, que não estou propondo que o jornal escolar seja tal coisa ou que deva ser de tal forma. Pelo contrário, espero que essas reflexões ajudem-nos (como professores) a pensar modos alternativos de conduzir o trabalho com o jornal e o letramento midiático. A visualização do modelo proposto, mesmo que ainda não testado anteriormente, já nos leva a refletir sobre os desafios e potencialidades do planejamento desse tipo de atividade nas aulas de Língua Portuguesa. Certamente não é possível trabalhar a produção do jornal escolar sem passar pelo trabalho com vários gêneros do jornal convencional. Não parece produtivo que se considerem todos esses gêneros em um único momento. Decidir quais gêneros ensinar, como e em qual momento é uma questão que exige planejamento, prática e uma reflexão sobre essa prática que vá realimentar o planejamento e, portanto, renovar e aperfeiçoar a prática.

\section{Referências}

AUGÉ, M. E. V. O jornal escolar: escrita e pensamento. 136 p. Dissertação (Mestrado em Educação) - Universidade Federal de Pelotas, 2008.

BAKHTIN, M. Os gêneros do discurso. In: Estética da criação verbal. Trad. Paulo Bezerra. São Paulo: Martins Fontes, 2006 [1953]. p. 261-306.

BALTAR, M. Rádio escolar: letramentos e gêneros textuais. Caxias do Sul: Educs, 2009.

BALTAR, M. Competência discursiva e gêneros textuais: uma experiência com o jornal de sala de aula. Caxias do Sul: Educs, 2004.

BALTAR, M. A competência discursiva através dos gêneros textuais: uma experiência com o jornal de sala de aula. 139 p. Tese (Doutorado em Letras) - Universidade Federal do Rio Grande do Sul, 2003.

BARONI, D. The New York Times, La Voz de Galicia e Folha de S. PauloExperiências de Jornal na escola. 110 p. Dissertação (Mestrado em Comunicação) - Universidade Paulista, 2005.

BARTON, D.; HAMILTON, M. Local literacies: reading and writing in one community. London: Routledge, 1998. 
BONINI, A. The distinction between news and reportage in the Brazilian journalistic context: a matter of degree. In: BAZERMAN, C.; BONINI, A.; FIGUEIREDO, D.C. (Org.). Genre in a changing world. West Lafayette, In: Parlor Press; Fort Collins, CO: WAC Clearinghouse, 2009. p. 196-222. Disponível em: <http://wac.colostate.edu/books/genre/>.

BONINI, A. As relaçôes constitutivas entre o jornal e seus gêneros: relato das pesquisas do 'Projeto Gêneros do Jornal'. In: BRAGA, S.; MORITZ, M. E. W.; REIS, M. S.; RAUEN, F. J. (Org.). Ciências da linguagem: avaliando o percurso, abrindo caminhos. Blumenau: Nova Letra, 2008. p. 21-45.

BONINI, A. Os gêneros do jornal: questôes de pesquisa e ensino. In: KARWOSKI, A. M.; GAYDECZKA, B.; BRITO, K. S. (Org.). Gêneros textuais: reflexões e ensino. 2 ed. Rio de Janeiro: Lucerna, 2006a. p. 57-71.

BONINI, A. Gêneros e projetos de trabalho no livro didático: uma análise de dois manuais. In: ENCONTRO DO CELSUL, 6, 2004, Florianópolis. Anais... Florianópolis: CELSUL, 2006b. p. 1-6. Disponível em: <http://www.celsul. org.br/Encontros/06/Individuais/85.pdf>.

BONINI, A. Os gêneros do jornal: o que aponta a literatura da área de comunicação no Brasil? Linguagem em (Dis)curso, Tubarão, v. 4, n. 1, p. 205-231, 2003 a.

BONINI, A. Gêneros textuais e currículo de Língua Portuguesa: propostas para o ensino médio na escola pública. Trabalhos em Lingüistica Aplicada, Campinas, v. 42, p. 81-93, 2003b.

BONINI, A. A. Metodologias de ensino de produção textual: a perspectiva da enunciação e o papel da psicolingüística. Perspectiva, v. 20, n. 1: "Expressando a Língua Portuguesa e seu ensino" organizado por Nilcéa Pelandré e Bernardete Biasi-Rodrigues, p. 23-47, 2002.

BONINI, A. O ensino de gêneros textuais: a questão das escolhas teóricas e metodológicas. Trabalhos em Lingüistica Aplicada, Campinas, n. 37, p. 7-23, 2001.

BONINI, A. Suporte, midia e hipergênero: os gêneros textuais e suas relações. (mimeo)

BONINI, A.; FIGUEIREDO, D.C.; BAZERMAN, C. (Org.). L1-Educational Studies in Language and Literature, International Association for the Improvement of Mother Tongue Education, v. 9, n. 2: Special issue "L1 studies in Brazil", 2009. Disponível em: <http://l1.publication-archive.com/public?fn=lookup\& repository=1\&string=Special\%20 issue \%20L1\%20Studies\%20in\%20Brazil $>$.

BONINI, A.; FURLANETTO, M.M. (Org.). Número Especial "Gêneros textuais e ensino-aprendizagem". Linguagem em (Dis)curso, v. 6, n. 3, p. 337$584,2006$. 
BRASIL. Ministério da Educação. Secretaria de Educação Fundamental. Parâmetros curriculares nacionais: terceiro e quarto ciclos do ensino fundamental: Língua Portuguesa. Brasília: MEC/SEF, 1998.

BRONCKART, J. P. Atividade de linguagem, textos e discursos. São Paulo: Educ, 1999 [1997].

BUCKINGHAM, David. Media education: literacy, learning and contemporary culture. Cambridge, UK: Polity Press; Oxford, UK: Blackwell, 2003.

CAVALCANTI, A. P. Pedagogia Freinet: uma experiência de construção da cidadania numa escola pública. 205 p. Dissertação (Mestrado em Educação) Universidade Federal do Rio Grande do Norte, 1999.

CAVALINI, E. S. A construção da escrita emancipatória. 112 p. Dissertação (Mestrado em Educação) - Universidade Federal de Pelotas, 2000.

CHEVALLARD, Y. On didactic transposition theory: some introductory notes. INTERNATIONAL SYMPOSIUM ON SELECTED DOMAINS OF RESEARCH AND DEVELOPMENT IN MATHEMATICS EDUCATION, Bratislava, 3-7 août 1988. Proceedings... Bratislava: [s.n.], 1989. p. 51-62.

COPE; B.; KALANTZIS, M. (Ed.). Multiliteracies: literacy learning and the design of social futures. London: Routledge, 2000.

COSSON, R. Letramento literário: teoria e prática: São Paulo: Contexto, 2006.

DELLISOLA, R. L. P. Retextualização e gêneros escritos. Rio de Janeiro: Lucerna, 2007.

DIONISIO, A. P.; MACHADO, A. R.; BEZERRA, M. A. (Org.). Gêneros textuais \& ensino. Rio de Janeiro: Lucerna, 2002.

DOLZ, J.; NOVERRAZ, M.; SCHNEUWLY, B. Seqüências didáticas para o oral e a escrita: apresentação de um procedimento. In: SCHNEUWLY, B.; DOLZ, J. et al. Gêneros orais e escritos na escola. Trad. e org. de Roxane Rojo e Glaís Sales Cordeiro. Campinas: Mercado de Letras, 2004. p. 95-128.

FARIA, M. A.Como usar o jornal na sala de aula. São Paulo: Contexto, 1996.

FARIA, M. A.O jornal na sala de aula. São Paulo: Contexto, 1989.

FARIA, M. A.; ZANCHETTA JR., J. Para fazer o jornal na sala de aula. São Paulo: Contexto, 2002.

FREINET, C. O jornal escolar. Lisboa: Editorial Estampa, 1974.

GAGO; P. C.; VIEIRA, L. S. L. O processo de retextualização a partir do gênero textual fábula: uma pesquisa participativa com alunos do $3^{\circ}$ ano do ensino fundamental. Linguagem em (Dis)curso, v. 6, n. 1, p. 45-62, 2006. 
GALARZA, D. K. Dando a palavra às crianças: uma experiência de trabalho com crianças de classe popular utilizando as técnicas Freinet do texto livre e do jornal escolar. Dissertação (Mestrado em Educação) - Universidade Federal do Rio Grande do Sul, 1988.

GERALDI, J. W. (Org.). Concepçôes de linguagem e ensino de português. (Org.). O texto na sala de aula. 2. ed. São Paulo: Ática, 1999 [1981a]. p. 39-46.

GERALDI, J. W. Unidades básicas do ensino de português. In: (Org.) O texto na sala de aula. 2. ed. São Paulo: Ática, 1999 [1981b]. p. 57-79.

HALTÉ, Jean-François. L'espace didactique et la transposition. Pratiques, Metz: Siege Social, ns. 97-98, p. 171-192, 1998. [tradução para o português publicada em Fórum Lingüistico, v. 5, n. 2, p. 117-139, 2008]

HERNANDEZ, F. Transgressão e mudança na educação: Os projetos de trabalho. Porto Alegre: Artmed, 1998.

HERNANDEZ, F.; VENTURA, M. A Organização do currículo por projetos de trabalho. Porto Alegre: Artmed, 1998.

IJUIM, J. K. Jornal escolar e vivências humanas: um roteiro de viagem. Bauru: Edusc, 2006.

IJUIM, J. K. Jornal escolar e vivências humanas - um roteiro de viagem. 239 p. Tese (Doutorado em Comunicação) - Universidade de São Paulo, 2002.

IJUIM, J. K. Jornal na escola: um instrumento de integração. 157 p. Dissertação (Mestrado em Comunicação) - Universidade de São Paulo, 1995.

ILARI, R. A lingüistica e o ensino de Lingua Portuguesa. São Paulo: Martins Fontes, 1997 [1985].

JOHNS, A. M. Text, role and context: developing academic literacies. Cambridge: Cambridge University Press, 1997.

JOHNS, A. M. Destabilizing and enriching novice students' genre theories. In: (Ed.). Genre in the classroom: multiple perspectives. New Jersey, N. J.: Lawrence Erlbaum, 2002. p. 237-246.

KARWOSKI, A. M.; GAYDECZKA, B.; BRITO, K. S. (Org.). Gêneros textuais: reflexōes e ensino. 2. ed. Rio de Janeiro: Lucerna, 2006. p. 57-71.

KAUFMAN, A. M.; RODRÍGUEZ, M. H. Escola, leitura e produção de textos. Porto Alegre: ARTMED, 1995.

KLEIMAN, A. B.; BALTAR, M. (Org.). Número especial "Letramento e formação de professores". Linguagem em (Dis)curso, v. 8, n. 2, p. 407-652, 2008. 
KLEIMAN, A. B.O processo de aculturação pela escrita: ensino da forma ou aprendizagem da função? In: KLEIMAN, A. B.; SIGNORINI, I. (Org.). O ensino e a formação do professor: alfabetização de jovens e adultos. Porto Alegre: Artmed, 2000. p. 223-243.

KLEIMAN, A. B. (Org.). Os significados do letramento: uma nova perspectiva sobre a prática social da escrita. Campinas: Mercado de Letras, 1995.

MARCUSCHI, L. A. Da fala para a escrita: atividades de retextualização. São Paulo: Cortez, 2001.

MIRANDA, A.S. O jornal escolar e a educação problematizadora: vislumbrando uma aproximação. UNIrevista, v. 1, n. 3, 2006. Disponível em: http:// www.alaic.net/ponencias/UNIrev_Miranda.pdf. Acesso em: 20 mar. 2008.

OLIVEIRA, M. S.; KLEIMAN, A. (Org.). Letramentos múltiplos: agentes, práticas, representaçôes. Natal: EDUFRN, 2008.

PORTAL do jornal escolar. Disponível em: <http://www.jornalescolar.org.br >. Acesso em: 16 out. 2009.

RODRIGUES, R. H. Pesquisa com os gêneros do discurso na sala de aula: resultados iniciais. Acta Scientiarum: language and culture, v. 30, p. 169-175, 2008. Disponível em: <www.periodicos.uem.br/ojs/index.php/ActaSciLang Cult/index>.

ROJO, R. Letramentos múltiplos, escola e inclusão social. São Paulo: Parábola, 2009.

SALUSTIANO, D. A. Nas entrenlinhas da notícia: o jornal escolar como estratégia de aprendizagem da língua materna. 300 p. Tese (Doutorado em Educação) Universidade Federal do Ceará, 2006.

SALUSTIANO, D. A. Jornal escolar como atividade de ensino-aprendizagem das funçôes sociais da lingua escrita. 160 p. Dissertação (Mestrado em Educação) Universidade Federal do Ceará, 2000.

SBRUSSI, M. P. B. P. O papel da imprensa escolar na produção textual: uma experiência com a pedagogia Freinet. 130 p. Dissertação (Mestrado em Educação) - Universidade Federal do Rio Grande do Norte, 2001.

SCHAUN, A. Educomunicação: reflexões e princípios. Rio de Janeiro: MAUAD, 2002.

SCHNEUWLY, B.; DOLZ, J. Os gêneros escolares: das práticas de linguagem aos objetos de ensino. In: SCHNEUWLY, B.; DOLZ, J. et al. Gêneros orais e escritos na escola. Trad. e org. de Roxane Rojo e Glaís Sales Cordeiro. Campinas: Mercado de Letras, 2004. p. 71-91.

SOARES, M. Letramento: um tema em três gêneros. Belo Horizonte: Autêntica, 1998. 
SOBREIRO, M.A. Célestin Freinet e Janusz Korczak, precursores do jornal escolar. Disponível em: <http://www.cesnors.ufsm.br/professores/carolcasali/projetosem-educomunicacao/celestrin $\% 20$ freinet $\% 20 \mathrm{e} \% 20$ janusz $\% 20$ korczak.pdf $>$. Acesso em: 20 mar. 2008.

STREET, B. Literacy in theory and practice. Cambridge : Cambridge University Press, 1984.

STÜPP, R. AN Escola 10 anos: uma história cheia de detalhes. A Notícia, n. 196, 12 out. 2008. Disponível em: <http://www.clicrbs.com.br/anoticia/jsp/ default 2 .jsp? $\mathrm{uf}=2 \&$ local $=18 \&$ source $=\mathrm{a} 2237172 . \mathrm{xml} \&$ template $=4187 . \mathrm{dwt} \&$ edition $=$ 10882\&section=1134>. Acesso em: 16 out. 2009.

TEIXEIRA, A. P. M. As propostas de Jornal na Educação e suas implicações com a formação da cidadania. INTERCOM, 2005. Anais do... Disponível em: <http://www.intercom.org.br/papers/nacionais/2005/resumos/R1662-1.pdf>. TEIXEIRA, A. P. M. Educação, comunicação e cidadania: interfaces para elaboração do jornal escolar. 142 p. Dissertação (Mestrado em Educação) Universidade Estadual Paulista, Araraquara, 2001.

TORQUATO, I. B. Jornalismo infantil: "Pinguinho de Notícia". 261p. Dissertação (Mestrado em Comunicação) - Universidade Estadual Paulista, Bauru, 2002.

TYNER, K. R. Literacy in a digital world: teaching and learning in the age of information. Mahwah, NJ: LEA, 1998.

ZEN, M. I. D. (Org.). Projetos pedagógicos: cenas da sala de aula. 2. ed. Porto Alegre: Mediação, 2002.

Recebido em 26 de julho de 2010. Aprovado em 3 de setembro de 2010. 